\title{
FUNCTIONAL HEALTH LITERACY OF STUDENTS OF THE MEDICAL UNIVERSITY - SOFIA
}

\author{
P. Pesheva*, A. Velkova, L. Georgieva, E. Georgieva, N. Hristov, M. Pravchanska \\ Department of Social Medicine, Faculty of Public Health, Medical University - Sofia, Bulgaria
}

\begin{abstract}
PURPOSE: The objective of this study is to examine the health literacy of medical students. METHODS: In October 2017 a cross-sectional study was conducted among a representative sample of second year medical students of the Medical University - Sofia. Health literacy of students was measured by an adapted version of the European Health Literacy Survey Questionnaire (EU-HLS-Q). RESULTS: Students demonstrated a good self-reported ability to find health information. However, they reported difficulties in understanding and assessing different aspects of health information. CONCLUSIONS: Although medical students assess their ability to search and find health information as good and very good, they find it difficult to interpret the information.
\end{abstract}

Key words: health information, find, understand, judge, evaluate, apply

\section{INTRODUCTION}

Health literacy is a complex phenomenon involving individuals, families, communities and systems. The standard definition of the term "health literacy", that connects its multiple aspects, was established by the HLSEU Consortium: "Health literacy is linked to literacy and entails people's knowledge, motivation and competencies to access, understand, appraise, and apply health information in order to make judgments and take decisions in everyday life concerning healthcare, disease prevention and health promotion to maintain or improve quality of life during the life course (1)."

Within the EU policy health literacy is a outstanding priority emphasizing the need to empower patients and to establish a culture of learning and of patient safety throughout healthcare systems, putting health literacy at the core of such a learning environment (2).

The results of the 2012 European Health Literacy Survey (HLS-EU) have shown that limited health literacy poses a challenge for the general EU population. Nearly every second person $(46,3 \%)$ in the participating European

\footnotetext{
*Correspondence to: Peshka A. Pesheva, Department of Social Medicine, Faculty of Public Health, 8 Bialo More Str.,

Sofia 1527, tel. + 359899690251, e-mail:

krlsn2003@yahoo.com
}

countries has limited health literacy and the differences between participating European countries are considerable. There is a real social health literacy gap, since there is a remarkable social gradient not only for health, but also for health literacy $(3,4)$.

Health literacy is a significant issue for Bulgaria. Data from the European Health Literacy Survey show that $61,4 \%$ of Bulgarians have limited health literacy, and Bulgaria ranks first in low health literacy among all participating countries (Netherlands, Germany, Austria, Spain, Ireland, Poland, Greece). The poor education and social status of Bulgarian population is considered the underlying cause. High or low literacy levels have different impacts on the individual and public health as well as on the efficiency of the health system. Low individual health literacy, means that Bulgarians may not be able to effectively exercise their choice when making healthcare decisions. Low individual health literacy is associated with higher use of curative health services, low levels of knowledge among consumers, poorer health outcomes, as well as adverse health outcome such as medication errors, misdiagnosis due to poor communication between providers and patients, low rates of treatment adherence, hospital readmissions, and other related complications or conditions. It has been estimated that people with low individual health literacy are between one-and-a-half and 
three times more likely to experience an adverse outcome. Low health literacy is associated with reduced use of preventive services and management of chronic conditions, and higher mortality. At the same time, people with higher health literacy levels demonstrate healthier behaviours, are more adherent to treatment, report less chronic illness, feel healthier, and live longer (3-6).

\section{PURPOSE}

The purpose of this study is to examine the health literacy of medical students and to find out how medical students gain access to, understand, appraise and use health information.

\section{METHODS}

In October 2017 a cross-sectional study was conducted among a representative sample of second year medical students of the Medical University - Sofia. Information was collected from 134 Bulgarian students. Health literacy of students was measured by an adapted version of the European Health Literacy Survey Questionnaire (EU-HLS-Q), which reflected self-reported health literacy. The questionnaire used selected items from the EU-HLS-Q as well as newly formulated items. It was also supplemented with items asking about demography and other characteristics of respondents. Following the EU-HLS-Q the majority of items were phrased as direct questions: "How easy/difficult would you say it is to" perform a given health related task. Respondents rated their perceived difficulty on a Likert scale with 4 points (very easy, fairly
PESHEVA P., et al. easy, fairly difficult, very difficult). An option was available for not answering the question.

Statistical data processing was carried out with the statistical package SPSS, version 23 using descriptive analysis and tests to assess relationship between variables. P-values of $\leq 0.05$ were considered as statistically significant.

\section{RESULTS}

\section{Characteristics of respondents}

Mean age of respondents was 20,04 years with a range from 18 years to 33 years. In the age distribution dominated students of the age 20 years $(67,9 \%)$. Female respondents $(62,7 \%)$ dominated male respondents $(37,3 \%)$.

Low weight was found in $50 \%$ of women and $10 \%$ of men and overweight in $2,43 \%$ of women and $20 \%$ of men. Obesity occurred in $2,43 \%$ of women and $2 \%$ of men.

Regarding tobacco smoking $56,7 \%$ of the students had never smoked, $27,6 \%$ of them were currently smokers, while $13,4 \%$ of them reported being smokers but having stopped smoking. During the last 12 months $81,3 \%$ of respondents had used any alcoholic beverages (beer, wine, spirits, cider or other) while the remaining $18,7 \%$ of them reported that they had not drank such drinks during the same period.

The majority of students defined their own health as "fair", followed by students that appreciated their own health as "good" and "bad" (Figure 1).

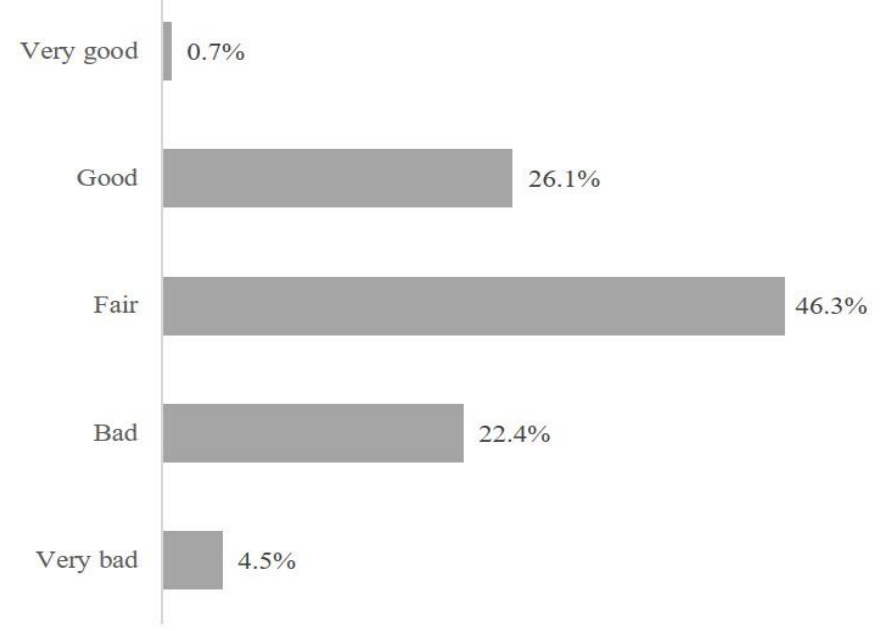

Figure 1. How is your health in general?

The majority of the students $(67,2 \%)$ had not had any long-term illness or health problem lasted for 6 months or more. However, 24,6\% of respondents reported only one and $8,2 \%$ of them more than one long-term illness or health problem lasted for 6 months.
Half of the students (50\%) had visited 1-2 times their doctor during the last 12 months but $28,4 \%$ of them had never been to the doctor during the last year (Figure 2). 


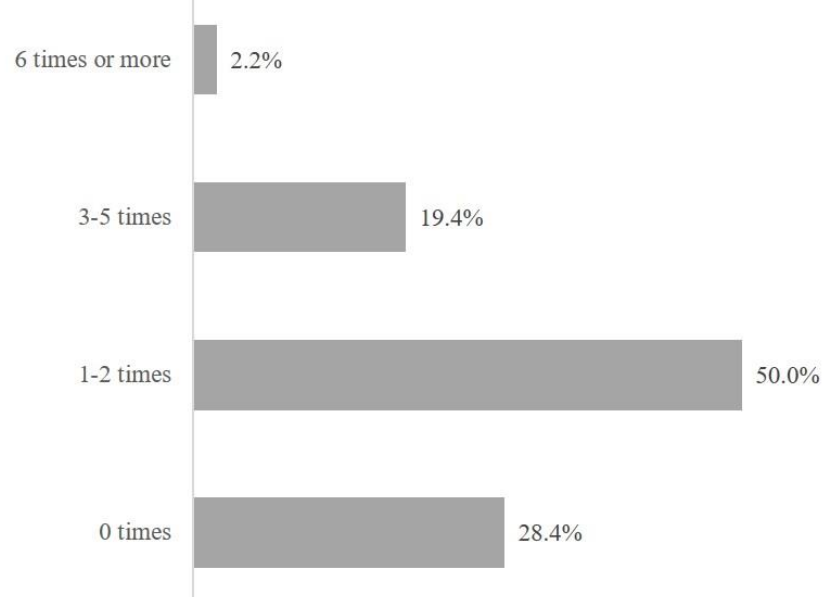

Figure 2. How many times have you been to the doctor in the last 12 months?

\section{Health literacy items}

The survey questionnaire encountered three main dimensions taking in account the complexity of health literacy skills: the ability to find health information; the ability to understand and judge health information; the ability to apply relevant health information in specific situations. It measured selfexperienced and self-rated abilities to perform health relevant tasks of information management and reflected self-evaluated health literacy competencies of medical students in relation to health literacy demands in specific background.

In respect to the percentage distributions on the difficulty-easiness scale there was considerable variation in item difficulty, ranging from $10,5 \%(\mathrm{Q} 3)$ to $64,2 \%(\mathrm{Q} 7)$ for "very easy", and from $0,7 \%(\mathrm{Q} 1,7,19)$ to $17,2 \%(\mathrm{Q} 9)$ for "very difficult". There was also considerably smaller percentage of respondents in the "very difficult" category (Table 1).

Percentages of "fairly easy" category ranged between 66,4\% (Q1) and 27,6\% (Q16) while "fairly difficult" category showed parentage distribution between 2,2\% (Q7,Q10) and $34,3 \%(\mathrm{Q} 12)$.

The questions on the difficulty of judging reliability of health information in the media $(\mathrm{Q} 9=17,2 \%$ very difficult $)$, on the ability to evaluate information on health risks in the media $(\mathrm{Q} 16=11,9 \%$ very difficult $)$ as well as the question on the ability to find information about vaccinations and health screenings (Q12 $=8,2 \%$ very difficult) are on average the most difficult items for the medical students in all three main dimensions of health literacy. On the other hand, item Q7 (to understand instructions from your doctor or pharmacist on how to take a prescribed medicine) was on average one of the easiest task with $2,9 \%$ of respondents indicating difficulties and 64,2\% of them indicating "very easy" category.

Items Q14 (understand health warnings about behaviour such as smoking, low physical activity and drinking too much $=61,9 \%$ very easy); item Q10 (follow instructions from your doctor or pharmacist $=59,7$ very easy); item Q19 (judge which everyday behaviour drinking, eating habits, exercise- is related to health $=55,2 \%$ very easy); item Q21 (join a sports club or exercise class if you want to $=50,7$ very easy) were also among the easiest tasks for medical students.

The majority of medical students reported high self-experienced and self-rated abilities to find health related information (very easy +fairly east category): $91 \%$ found it easy to find information about symptoms of illnesses (Q1); $76,8 \%$ found it easy to find information about treatments options (Q2); 79,9\% found it easy to find information on how to prevent or manage unhealthy behaviour such as smoking, low physical activity and drinking too much (Q11). The greatest difficulties (very difficult + fairly difficult) in finding information area for medical students were related with finding information about vaccinations and health screening programs $(\mathrm{Q} 12=42,5 \%)$.

Although that on average medical students demonstrated high self-rated ability to find health information, they reported difficulties in understanding and assessing different aspects of health information: 39,6\% of respondents found it difficult to judge the advantages and disadvantages of treatment alternatives (Q8); $45,6 \%$ had difficulties in judging the reliability of media information about diseases (Q9); $41 \%$ found it difficult to assess the reliability of 
information on health risk in the media (Q16); $22,4 \%$ had difficulties to judge how reliable health warnings are such as smoking, low physical activity and drinking too much alcohol(Q15); 30,6\% of them had difficulties in understanding information on food packages (Q17).

The self-rated abilities to apply relevant health information in specific situations were also
PESHEVA P., et al. perceived in the category "very easy" and "fairly easy" by medical students. More than half of them declared that to join a sports club or exercise class is easy (Q21=80,6\%). To influence their own living conditions that affect their health and well being as drinking and eating habits, exercise is recognized also as easy by $73,1 \%$ of the students (Q22).

Table 1. Percentages of questionnaire items

\begin{tabular}{|c|c|c|c|c|c|}
\hline \multicolumn{6}{|c|}{ How easy/difficult would you say it is: } \\
\hline & $\begin{array}{l}\text { Very } \\
\text { easy }\end{array}$ & $\begin{array}{l}\text { Fairly } \\
\text { easy }\end{array}$ & $\begin{array}{c}\text { Fairly } \\
\text { difficult }\end{array}$ & $\begin{array}{c}\text { Very } \\
\text { difficult }\end{array}$ & $\begin{array}{l}\text { Don't } \\
\text { know }\end{array}$ \\
\hline & $N / \%$ & $N / \%$ & $N / \%$ & $N / \%$ & $N / \%$ \\
\hline Q1.To find information about symptoms of illnesses that concern you? & $33 / 24,6$ & $89 / 66,4$ & $10 / 7,5$ & $1 / 0,7$ & $1 / 0,7$ \\
\hline Q2. To find information about treatments of illnesses that concern you? & $18 / 13,4$ & $85 / 63,4$ & $29 / 21,6$ & $2 / 1,5$ & - \\
\hline Q3. To find out what to do in case of a medical emergency? & $14 / 10,5$ & $77 / 57,5$ & $34 / 25,4$ & $5 / 3,7$ & $4 / 3,0$ \\
\hline $\begin{array}{l}\text { Q4. To find out where to get professional help (such as doctor, pharmacist, } \\
\text { psychologist) when you are ill? }\end{array}$ & $53 / 39,6$ & $65 / 48,5$ & $15 / 11,2$ & - & $1 / 0,7$ \\
\hline Q5. To understand what your doctor says to you? & $53 / 39,6$ & $67 / 50,0$ & $14 / 10,4$ & - & - \\
\hline Q6. To understand the leaflets that come with your medicine? & $45 / 33.6$ & $51 / 38,1$ & $31 / 23,1$ & $7 / 5,2$ & - \\
\hline $\begin{array}{l}\text { Q7. To understand your doctor's or pharmacist's instruction on how to take a } \\
\text { prescribed medicine }\end{array}$ & $86 / 64,2$ & $44 / 32,8$ & $3 / 2,2$ & $1 / 0,7$ & - \\
\hline $\begin{array}{l}\text { Q8. To judge the advantages and disadvantages of different treatment } \\
\text { options? }\end{array}$ & $15 / 11,1$ & $60 / 44,8$ & $45 / 33,6$ & $8 / 6,0$ & $6 / 4,5$ \\
\hline $\begin{array}{l}\text { Q9. To judge if the information about illness in the media (TV, Internet or } \\
\text { other media) is reliable? }\end{array}$ & $27 / 20,2$ & $42 / 31,3$ & $38 / 28,4$ & $23 / 17,2$ & $4 / 3,0$ \\
\hline Q10. To follow instructions from your doctor or pharmacist? & $80 / 59,7$ & $49 / 36,6$ & $3 / 2,2$ & $2 / 1,5$ & - \\
\hline $\begin{array}{l}\text { Q11. To find information about how to manage unhealthy behaviour such as } \\
\text { smoking, low physical activity and drinking too much? }\end{array}$ & $56 / 41,8$ & $51 / 38,1$ & $22 / 16,4$ & $4 / 3,0$ & $1 / 0,7$ \\
\hline $\begin{array}{l}\text { Q12. To find information about vaccinations and health screenings that you } \\
\text { should have? }\end{array}$ & $29 / 21,6$ & $46 / 34,3$ & $46 / 34,3$ & $11 / 8,2$ & $2 / 1,5$ \\
\hline $\begin{array}{l}\text { Q13. To find information on how to prevent or manage conditions like being } \\
\text { overweight, high blood pressure or high cholesterol? }\end{array}$ & $56 / 41,8$ & $62 / 46,3$ & $12 / 9,0$ & $3 / 2,2$ & $1 / 0,7$ \\
\hline $\begin{array}{l}\text { Q14. To understand health warnings about behaviour such as smoking, low } \\
\text { physical activity and drinking too much? }\end{array}$ & $83 / 61,9$ & $40 / 29,9$ & $8 / 6,0$ & $3 / 2,2$ & - \\
\hline $\begin{array}{l}\text { Q15. To judge how reliable health warnings are, such as smoking, low physical } \\
\text { activity and drinking too much? }\end{array}$ & $48 / 35,8$ & $52 / 38,8$ & $28 / 20,9$ & $2 / 1,5$ & $4 / 3,0$ \\
\hline $\begin{array}{l}\text { Q16. To judge if the information on health risks in the media (TV, Internet or } \\
\text { other media) is reliable? }\end{array}$ & $39,29,1$ & $37 / 27,6$ & $39 / 29,1$ & $16 / 11,9$ & $3 / 2,2$ \\
\hline Q17. To understand information on food packaging? & $33 / 24,6$ & $60 / 44,8$ & $32 / 23,9$ & $9 / 6,7$ & - \\
\hline $\begin{array}{l}\text { Q18. To understand information in the media (Internet, newspapers, } \\
\text { magazines) on how to get healthier? }\end{array}$ & $52 / 38,8$ & $56 / 41,8$ & $16 / 11,9$ & $6 / 4,5$ & $4 / 3,0$ \\
\hline $\begin{array}{l}\text { Q19. To judge which everyday behaviour (drinking and eating habits, exercise } \\
\text { etc.) is related to your health? }\end{array}$ & $74 / 55,2$ & $53 / 39,6$ & $6 / 4,5$ & $1 / 0,7$ & - \\
\hline Q20. To judge how your housing conditions help you to stay healthy? & $49 / 36,6$ & $58 / 43,3$ & $22 / 16,7$ & $3 / 2,2$ & $2 / 1,5$ \\
\hline Q21. To join a sports club or exercise class if you want to? & $68 / 50,7$ & $40 / 29,9$ & $21 / 15,7$ & $3 / 2,2$ & $2 / 1,5$ \\
\hline $\begin{array}{l}\text { Q22. To influence your living conditions that affect your health and well being? } \\
\text { (Drinking and eating habits, exercise etc.) }\end{array}$ & $36 / 26,8$ & $62 / 46,3$ & $30 / 22,4$ & $6 / 4,5$ & 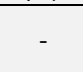 \\
\hline
\end{tabular}

\section{DISCUSSION}

Health literacy is important for all players in the healthcare system. It is important for users of health care because it affects their capacity to make decisions and take action to manage their own health and health care. It is important for healthcare providers because it affects the way that they manage their relationships with patients and deliver health care. It is also important for broader society because health literacy contributes to population health and productivity (7).

However, health literacy is much more than just knowledge, understanding, skills and abilities to use health information. It has two essential components: individual health literacy and the health literacy environment. These two components reflect the two predominant factors that influence the way that a person accesses, understands, appraises and applies information. Individual health literacy includes the skills, knowledge, motivation and capacity of a person to access, understand, appraise and apply information to make effective decisions about health and health care and take appropriate action. Health literacy environment reflects the infrastructure, policies, processes, materials, people and relationships that build up the health system 
and have an impact on the way in which people access, understand, appraise and apply health-related information and services $(8,9)$.

Modern health information and health systems have become increasingly complex and harder to understand. That's way health literacy is crucial in the effective communication between patients and health professionals (10). Studies on the health literacy of health professionals, including medical students are limited. These limited researches show that among health professionals there are limitations and gaps in knowledge, understanding and evaluation capacities related to individual and to environmental health literacy (11-13).

Today's generation of medical students have access to multiple sources of health information of varying quality. But the quick access to information sources does not imply that students have the necessary skills to understand and judge the adequacy of published health information.

The main limitation of the study evolves from the self-experienced and self-rated nature of questionnaire items which enable the students to exaggerate their own competencies to find, judge and apply reliable health-related information.

\section{CONCLUSIONS}

Medical students demonstrate good level of self-reported health literacy but some week points are found. Although medical students assess their ability to search and find health information as good and very good, they find it difficult to interpret this information. However, good health literacy in all its aspects is required by medical students as future health professionals, on the one hand, and as users of health services, on the other hand.

This study shows that health literacy of medical students needs to be improved in some of its most important aspects. In this respect medical university should play a leading role and pay more attention to the cultivation of health literacy of medical students.

\section{REFERENCES}

1. Sorensen, K., Van den Broucke, S., Fullam, J., Doyle, G., Pelikan, J., Slonska, Z., Brand, H., Health literacy and public health: A systematic review and integration
PESHEVA P., et al. of definitions and models. BMC Public Health, 12:80-94, 2012.

2. Commission of the European Communities, Together for Health: A Strategic Approach for the EU 2008-2013. EC, 2007.

3. Sorensen, K., Pelikan, J., Rotlin, F., Ganahl, K., Slonska, Z., Doyle, G., Fullam, J., Kondilis, B., Agrafiotis, D., Uiters, E., Falcon, M., Mensing, M., Tchamov, K., Van den Broucke, S., Brand, H., Health literacy in Europe: comparative results of the European health literacy survey (HLSEU). Eur J Public Health, 25(6):10531058, 2015.

4. Pelikan, J., Rotlin, F., Ganahl, K., Comparative report of health literacy in eight EU member states: The European health literacy survey HLS-EU. HLS-EU Consortium, 2012.

5. Nielsen-Bohlman, L., Panzer, A., Kindig, D., Health Literacy: A Prescription to End Confusion. Nat Acad Press, Washington DC, USA, 2004.

6. Vernon, J., Trujillo, A., Rosenbaum, S., DeBuono, B., Low health literacy: Implications for national health policy. SPHHS, Washington, DC, USA, 2007.

7. Australian Commission on Safety and Quality in Health Care, Health literacy: Taking action to improve safety and quality. ACSQHC, Sydney, Australia, 2014.

8. Berkman, N. et al., Literacy and Health Outcomes. AHRQ, Rockville, MD, 2004.

9. Bopp, M., Minder, C., Mortality by education in German speaking Switzerland, 1990-1997: results from the Swiss National Cohort. Int J of Epid, 32:346-354, 2003.

10.Parker, R., Measuring health literacy: Why? So what? Now what? In: Hernandez L, (ed), Measures of Health Literacy: Roundtable on Health Literacy. National Academies Press, Washington, DC, pp 91-98, 2009.

11.Zhang, Y., Zhang, F., Hu, P., Huang, W., Lu, L., Bai, R., Exploring Health Literacy in Medical University Students of Chongqing, China: A Cross-Sectional Study. PLoS ONE, 11(4):e0152547, 2016.

12.Cormier, C., Kotrlik, J., Health literacy knowledge and experiences of senior baccalaureate nursing students. $J$ Nurs Educ, 48(5):237-48, 2009.

13.Wang, W., Hou, Y., Hu, N., Zhang, D., Tao, J., Man, Y., A cross-sectional study on health-related knowledge and its predictors among Chinese vocational college students. BMJ Open, 4(10):e005182, 2014. 